\title{
Banding cytogenetic analysis in pediatric patients with acute lymphoblastic leukemia (ALL) in a Brazilian population
}

\author{
Erica Aires Gil ${ }^{1 *}$, Tirzah Braz Petta Lajus², Taissa Maria Oliveira de Moura', Juliana Mendonça Freire', \\ Andréa Luciana Araújo da Fernandes', Gioconda Dias Rodrigues Leão', Edlene Melo Reis do Nascimento', \\ Gabriela Vasconcelos Andrade de Alves ${ }^{1}$ and Geraldo Barroso Cavalcanti Júnior ${ }^{1}$
}

\begin{abstract}
Background: Cytogenetic studies in Brazilian population about childhood acute lymphoblastic leukemia (ALL), the most common childhood malignancy, are scarce. Moreover, Brazilian race is very heterogeneous and is made by the confluence of people of several different origins, from the original Native Brazilians, with the influx of Portuguese colonizers, Black African slaves, and recent European, Arab and Japanese immigration. The purpose of this prospective, multicentric study was to assess the sociodemographic, clinic and cytogenetic characteristics of the children treated for ALL in the Northeast region of Brazil.

Results: This study includes thirty patients between 4 months and 17 years old treated for ALL from January 1st, 2009 to November 30th, 2010. Cytogenetic analysis showed that in nineteen out of thirty patients (64\%) presented some chromosome abnormalities, in which $53 \%$ corresponds to numerical abnormalities, $21 \%$ structural and numerical abnormalities, and 26\% only structural changes. Moreover, seven patients presented complexes karyotype not yet described in the literature. Taken together these results show the importance of the cytogenetic analysis in ALL pediatric patients and illustrates that the studied population presented unexpected complexes karyotypes which were correlated to poor outcome.

Conclusion: The results demonstrate the importance of banding cytogenetics for ALL diagnosis despite the use of most modern techniques such as FISH and aCGH, and provide reliable insight into the ALL in Brazil.
\end{abstract}

Keywords: (3 a 6), Epidemiology, Acute lymphoblastic leukemia, Childhood, Banding cytogenetic analysis

\section{Background}

Acute lymphoblastic leukemia (ALL) comprises a group of neoplasms characterized by clonal proliferation and accumulation in the blast, hematopoietic immature cells in the bone marrow. ALL is a disease characterized by abnormal clonal proliferation of lymphoid precursors which lose their ability to differentiate. It is the most common malignancy in childhood, accounting for $80 \%$ of all leukemia. Although it can occur at any age, its incidence is highest among children from 2 to 5 years at a rate of about $70 \%$, decreasing among adolescents and

\footnotetext{
* Correspondence: erica.gil@ig.com.br

'Departamento de Análises Clínicas e Toxicológicas/ Laboratório de Imunologia, Universidade Federal do Rio Grande do Norte/, Rua Gen, Gustavo Cordeiro De Farias S/N. Petrópolis, CEP 59010-180, Natal, RN, Brazil Full list of author information is available at the end of the article
}

young adults. The most useful prognostic indicators in ALL are age, white blood cell count (WBC) and immunologic markers. Cytogenetic analysis is of fundamental importance in the diagnosis, therapy, in monitoring post-transplant bone marrow and to assess prognosis. It is now possible to correlate the karyotype with other recognized prognostic factors and to show that cytogenetic studies can increase the precision of other clinical prognostic features. Unfortunately, banding cytogenetic analysis of leukemia is technically demanding, especially in the case of ALL in infants. Clonal abnormalities are difficult to identify because of frequent failure of standard chromosomepreparing protocols. Moreover, clonal selection leads to a high proportion of normal metaphases, masking abnormal cells when a limited number of metaphases are analyzed 
[1]. Therefore, the chromosomal classification of ALL is often incomplete, and it is not clear whether the abnormalities detected in a few analyzable metaphases are representative of the whole leukemic clone $[2,3]$.

Banding cytogenetic studies have identified numerical and structural chromosomal abnormalities related to the disease's pathophysiologic characteristics. Frequency of these abnormalities varies between pediatric and adult patients. In children, pseudodiploidy is the most frequent (40\%), followed by hyperdiploidy with 51-65 chromosomes (27\%), hyperdiploidy with 47-50 chromosomes (15\%), hypodiploidy (6\%), near-haploidy (1\%), and the tetraploids $(1-2 \%)[4,5]$. It has also been demonstrated that the frequency with which chromosomal abnormalities are observed varies among populations. In the Hindu population, hyperdiploidy is infrequent (15\%), in contrast with the high frequency of hypodiploidy (38.4\%). This behavior has been attributed to unknown ethnic differences and geographic factors [6,7].

We aimed to study the cytogenetic profile in pediatric patients in several health institutions in the Brazilian Northeast region, which is a very heterogeneous race and no data on this feature is available in the literature.

\section{Aim}

To determine the cytogenetics profile of patients with ALL during the period from January 1st, 2009 to November 30th, 2010 in the Northeast of Brazil.

\section{Results}

\section{Patients characteristics}

The sample comprised 30 patients diagnosed for ALL between one and ten years old. The clinical characteristics of the ALL patient populations are provided in Table 1. Thirty seven percent (37\%) were in the range between two and five years old, with a mean age of 7,5 years old. Regarding the sex, the male:female ratio was $1,3: 1$. The complexity of racial classifications in Brazil reflects the extent of miscegenation in Brazilian society, more people would report themselves as white and pardo, which is a mixed race of white and black people found only in Brazil ( $47.7 \%$ and $42.4 \%$ of the population as of 2010 , respectively). For this reason we have separated the studied population by skin color. Skin color was predominantly white (50\%) followed by pardo (33\%) and black (17\%).

According to medical records, the most common finding of physical examination was hepatomegaly (73\%), splenomegaly $(70 \%)$ and lymphadenopathy (37\%). The samples (bone marrow and peripheral blood) were collected previous treatment in $83 \%$ of patients, whereas $17 \%$ were submitted to collection after treatment has been initialized. Seventy three percent (73\%) of the patients' hemoglobin levels were less than $10 \mathrm{~g} / \mathrm{dL} ; 60 \%$ of patients showed white blood cell (WBC) counts below $10.000 / \mu \mathrm{L}$ and $40 \%$
Table 1 An unusual T-cell childhood acute lymphoblastic leukemia harboring a yet unreported near-tetraploid karyotype

\begin{tabular}{|c|c|c|c|c|c|c|}
\hline $\mathbf{N}$ & Sex & Age (y) & $\begin{array}{l}\text { Skin } \\
\text { color }\end{array}$ & $\begin{array}{c}\mathrm{BCC} \\
(\mathrm{g} / \mathrm{dL})\end{array}$ & $\begin{array}{l}\text { Leucometry } \\
\text { values (ul) }\end{array}$ & $\begin{array}{l}\text { Platelets } \\
\text { values (ul) }\end{array}$ \\
\hline 1 & $F$ & 4 & White & 7,3 & 20200 & 32000 \\
\hline 2 & $\mathrm{~F}$ & 7 & White & 12 & 11000 & 44000 \\
\hline 3 & M & 5 & Pardo & 5,9 & 34700 & 33000 \\
\hline 4 & M & 16 & White & 13 & 4600 & 63000 \\
\hline 5 & $\mathrm{~F}$ & 6 & White & 7,5 & 3100 & 32000 \\
\hline 6 & $\mathrm{~F}$ & 4 & Black & 8 & 4300 & 283000 \\
\hline 7 & M & 3 & Black & 9 & 5800 & 336000 \\
\hline 8 & $F$ & 5 & White & 10,2 & 7800 & 165000 \\
\hline 9 & M & 12 & White & 14 & 4400 & 249000 \\
\hline 10 & M & 16 & Black & 8 & 1500 & 12000 \\
\hline 11 & M & 17 & Pardo & 15 & 2800 & 19000 \\
\hline 12 & $F$ & 15 & White & 8 & 3000 & 52000 \\
\hline 13 & M & 8 & Pardo & 11,3 & 3200 & 44900 \\
\hline 14 & $\mathrm{~F}$ & 0,4 & Black & 7,8 & 96600 & 65000 \\
\hline 15 & M & 3 & Pardo & 9,2 & 21900 & 55000 \\
\hline 16 & $F$ & 3 & Black & 7,3 & 7900 & 26000 \\
\hline 17 & M & 5 & Pardo & 6,8 & 35900 & 54000 \\
\hline 18 & M & 2 & White & 5,7 & 6300 & 7000 \\
\hline 19 & M & 3 & White & 8,4 & 50900 & 37000 \\
\hline 20 & $\mathrm{~F}$ & 1 & Pardo & 5,4 & 45700 & 26000 \\
\hline 21 & M & 17 & Pardo & 7,1 & 60000 & 12000 \\
\hline 22 & $\mathrm{~F}$ & 7 & Pardo & 9,4 & 33200 & 83000 \\
\hline 23 & $F$ & 3 & White & 7,5 & 5600 & 45000 \\
\hline 24 & $\mathrm{~F}$ & 6 & White & 9,4 & 25000 & 38000 \\
\hline 25 & $\mathrm{~F}$ & 17 & White & 11,3 & 6500 & 18000 \\
\hline 26 & $M$ & 2 & White & 8,5 & 7400 & 45000 \\
\hline 27 & M & 0,4 & Pardo & 10 & 13500 & 60000 \\
\hline 28 & $M$ & 6 & White & 7,8 & 2100 & 42000 \\
\hline 29 & $M$ & 5 & White & 6,9 & 5600 & 77000 \\
\hline 30 & M & 16 & Pardo & 11,5 & 5300 & 160000 \\
\hline
\end{tabular}

above this value. Considering the population who showed WBC above $10.000 / \mu \mathrm{L}, 10 \%$ were above $50.000 / \mu \mathrm{L}$. Thrombocytopenia was observed in $83 \%$ of cases (Table 1 ).

\section{Cytogenetics studies}

Cytogenetic studies using G-banding techniques were performed in 30 samples from ALL patients, where nineteen $(64 \%)$ presented chromosomal alterations in the bone marrow (BM) and peripheral blood (PB), seven patients $(23 \%)$ had normal karyotype and in four patients $(13 \%)$ it was not possible to analyze due to the absence of cell growth (MI - mitotic index zero). Immunophenotype analysis showed that $93 \%$ of patients had B-lineage 
ALL and 7\% T- lineage ALL. Among the B-lineage ALL, the majority of cases (83\%) were classified as pre-B (Table 2). The small percentage of patients with T-ALL may be associated with the proportion of adolescent patients in this sample which were over 10 years.

Considering the nineteen patients who presented some type of chromosomal abnormality, 53\% were numerical abnormalities, $21 \%$, were structural and numerical abnormalities and $26 \%$ of the patients presented only structural changes. In fourteen patients who presented numeric chromosomal abnormalities and numeric alteration with additional structural change, hyperdiploidy was detected in eight patients (57\%); hyperdiploidy with additional change in three patients (22\%); hypodiploidy in two patients (14\%), and finally, hypodiploidy with additional changes in one patient (7\%) (Table 2). Unusual or novel

Table 2 Results from G-banding technique related to imunophenotype of each patient (1-30)

\begin{tabular}{|c|c|c|c|c|}
\hline $\mathbf{N}$ & Karyotype & Cell type & $\begin{array}{c}\text { Classification of } \\
\text { cytogenetic alteration }\end{array}$ & Ploidy \\
\hline 1 & $42 \sim 45, X X,-3[3],-13[3],-20[4][c p 7] / 46, X X[13]$ & ALL pre-B (L1) & Numerical & Hyperdiploidy \\
\hline 3 & $\begin{array}{c}45 \sim 56, X Y,+4[3],+8[4],+11[3],+18[4],+20[3], \\
+21[4][\mathrm{cp} 20] / 46, X Y[05]\end{array}$ & ALL pre-B $(L 1)$ & Numerical & Hyperdiploidy \\
\hline 4 & $46, X Y[20]$ & ALL pre-B (L3) & Normal & - \\
\hline 5 & $46, X X[13]$ & ALL pre-B (L1) & Normal & - \\
\hline 6 & $46, X X[23]$ & ALL pre-B $(L 1)$ & Normal & - \\
\hline 7 & $46, X Y$, del(4)(p14?) [09] / 46,XY [11] & ALL pre-B $(L 1)$ & Structural & Pseudodiploidy \\
\hline 8 & $\begin{array}{c}49 \sim 58, X X,+5[4],+9[3],+11[3],+15[4],+21[4], \\
+22[3][\mathrm{cp} 9] / 46, X X[02]\end{array}$ & ALL pre-B $(L 1)$ & Numerical & Hyperdiploidy \\
\hline 9 & $46, X Y[23]$ & ALL pre-B $(\mathrm{L} 1)$ & Normal & - \\
\hline 11 & $48, X Y, t(1 ; 3)(q 32 ; q 27),+16,+\operatorname{mar}[09] / 46, X Y[14]$ & ALL pre-B $(L 2)$ & Numerical + structural & Hyperdiploidy+add \\
\hline 12 & $\begin{array}{c}49 \sim 87, \mathrm{XX},+1[5],+3[4],+5[5],+7[5],+10[4],+12[6] \\
+13[04], \operatorname{add}(14)(\mathrm{q} 32 ?), \mathrm{add}(16)(\mathrm{p} 13.3),+18[6],+19[4] \\
+20[3],+21[6],+22[5][\mathrm{cp} 30]\end{array}$ & ALL Pre-B (L1) & Numerical + structural & Hyperdiploidy+add \\
\hline 13 & $\begin{array}{c}49 \sim 54, \mathrm{XY},+3[3],+5[4],+8[4],+10[3],+17[4] \\
+21[4][\mathrm{cp} 11] / 46, \mathrm{XY}[04]\end{array}$ & ALL pre-B $(L 3)$ & Numerical & Hyperdiploidy \\
\hline 14 & $46, X X$,del(11)(q23) [17] & ALL pre-B (L1) & Structural & Pseudodiploidy \\
\hline 15 & $41 \sim 45, X Y,-5[3],-7[3],-21[4][\mathrm{cp} 13] / 46, X Y[07]$ & ALL pre-B (L1) & Numerical & Hypodiploidy \\
\hline 16 & $\begin{array}{c}50 \sim 61, X X,+2[3],+4[4],+10[4],+12[3],+16[4],+19[5], \\
+21[4][\mathrm{cp} 7] / 46, \mathrm{XX}[05]\end{array}$ & ALL pre-B (L1) & Numerical & Hyperdiploidy \\
\hline 17 & $\begin{array}{c}48 \sim 60, X Y,+3[4],+5[5],+7[4],+13[4],+17[3],+20[4], \\
+21[4][\mathrm{cp} 22] / 46, \mathrm{XY}[05]\end{array}$ & ALL pre-B $(\mathrm{L} 1)$ & Numerical & Hyperdiploidy \\
\hline 18 & $49 \sim 58, X Y,+1[4],+6[4],+7[5],+22[3][\mathrm{cp} 9] / 46, X Y[11]$ & ALL pre-B (L1) & Numerical & Hyperdiploidy \\
\hline 19 & $\begin{array}{c}\text { 46,XY, dup(1)(q31q44) [12] / 46,XY, dup(13)(q13q34) } \\
{[05] / 46, X Y, \operatorname{der}(21) t(7 ; 21)(q 21 q 36 ; q 22.3)[04] / 46, X Y[04]}\end{array}$ & $A L L-B(L 3)$ & Structural & Pseudodiploidy \\
\hline 20 & $46, X X,-7,+\operatorname{der} 7 t(7 ; ?)(q 31 ; ?)[30]$ & ALL pre-B (L1) & Numerical + structural & Pseudodiploidy \\
\hline 23 & $\begin{array}{c}53 \sim 62, X X,+5[4],+8[4],+12[3],+16[4],+18[3] \\
+20[4],+21[4][\mathrm{cp} 7] / 46, X X[15]\end{array}$ & ALL-B (L2) & Numerical & Hyperdiploidy \\
\hline 24 & $46, X X[19]$ & ALL pre-B $(L 3)$ & Normal & - \\
\hline 25 & $46, X X, t(9 ; 22)(q 34 ; q 11), \operatorname{add}(14)(q 32)[20]$ & ALL pre-B (L1) & Structural & Pseudodiploidy \\
\hline 26 & $\begin{array}{c}47, \mathrm{XY}, \mathrm{i}(7)(\mathrm{q} 10),+21 \mathrm{c}[22] / 48, \mathrm{idem},+\operatorname{mar}[4] / 48, \\
\mathrm{XY}, \mathrm{i}(7)(\mathrm{q} 10),+8,+21 \mathrm{c}[03]\end{array}$ & ALL pre-B (L1) & Numerical + structural & Hyperdiploidy+add \\
\hline 27 & $46, X Y[20]$ & $A L L-T(L 2)$ & Normal & - \\
\hline 28 & 38 45,XX, t(9;14), (q22?;q32?), del(20)(q?) [21] & ALL pré-B (L2) & Numerical + strutural & Hypodiploidy+add \\
\hline 29 & $46, X Y[20]$ & ALL pré-B & Normal & - \\
\hline 30 & $36 \sim 45, X Y,-4[3],-7[4],-9[3],-11[3],-22[4]$ [cp23] / 46,XY [03] & ALL pré-B & Numerical & Hypodiploidy \\
\hline
\end{tabular}

Legend: Samples 2, 10, 21 and 22 had null Mitotic Index $(\mathrm{Ml}=0)$. Complex karyotypes are highlighted in bold character in the table ( $\mathrm{N}=7)$. $\mathrm{L} 1$ : acute lymphoblastic leukemia type 1; L2: acute lymphoblastic leukemia type 2; L3: acute lymphoblastic leukemia type 3. inv - inversion; mar - marker chromosome; $t$ - translocation; $\mathrm{i}$ - isochromosome; add - additional chromosome; dup - duplication; der - derivative chromosome; Ph+ - Philadelphia chromosome; del - deletion; $\mathrm{p}$ - short arm of the chromosome; q - long arm of the chromosome, [ ] cells number analyzed. Complex karyotype are highlighted in the table $(\mathrm{N}=7)$. 
cytogenetic abnormalities were found in 7 patients (23\%). The karyotypes included in these cases presented hyper or hypodiploidy with additional modifications, in addition to the presence of cells with chromosomal markers (Table 2). Patient 26 is a child with Down syndrome (DS) and acute lymphoblastic leukemia (ALL) and is classified as complex karyotype for presenting three different clones.

\section{Discussion}

Leukemia is the most common malignant neoplasms in childhood, accounting for approximately 33\% of all malignancies in children under 14 years. Leukemia incidence affects the $0-14$ years old population with a frequency of $1 / 25.000$ individuals/ year, and the risk of developing the disease within the first 10 years is $1 / 2.880$. After the discovery by Casperson [8] and Seabright [9] of banding techniques, cytogenetic studies showed that about $50 \%$ of chromosomal abnormalities could be found in acute leukemia. Several prospective studies using banding techniques, have shown that the incidence of chromosomal abnormalities varies between $55-94 \%$, and found that some changes are specific to particular cell subtype characterized by immunophenotyping $[10,11]$.

Considering our results, where fifteen patients presented numerical chromosomal anomalies and numerical structural change, the hyperdiploidy was observed in ten patients $(67 \%)$, which showed $54 \%$ only hyperdiploidy and $13 \%$ with hyperdiploidy with additional changes, whereas hypodiploidy was found in $33 \%$ of patients. Of these, $13 \%$ had some structural change. The additional structural changes found were translocation, addition, duplication and the presence of chromosome marker. Pérez-Vera et al. [12] found that $22 \%$ patients presented normal karyotype and $74 \%$ had some cytogenetic abnormalities. Pui et al. [13] evaluated children diagnosed with ALL and found hyperdiploidy in $26 \%$ of the patients. In $62 \%$ of these cases were also detected chromosomal structural changes.

According to the literature, it is considered complex karyotypes more than one chromosomal abnormality and/ or an alteration which has not yet been described. We observed seven novel complex karyotypes, among these, a translocation between chromosomes 9 and $22(\mathrm{Ph}+)$ with additional chromosome 14, duplication of chromosomes $1 \mathrm{q}$ and $13 \mathrm{q}$, and a derivative of chromosome 21 translocated to chromosome 7 , forming a derivative of chromosome 7. It is important to highlight that these complex karyotypes are considered unfavorable outcome. One possible reason could be due to loss, gain or exchange of genes that can promote often resistant to treatment. The presence of the Philadelphia chromosome $(\mathrm{Ph}+)$ or 9:22 translocation is usually found in about $3-5 \%$ of the pediatric ALL, and is a modification of poor prognosis [14]. It was observed the presence of a marker chromosome in three analyzed karyotype. The marker chromosomes are complex rearrangements, usually consisting of centromeric heterochromatin, but may contain up to part of a chromosome gene. It is practically impossible to establish a precise relationship between the presence of this type of chromosome and the phenotype of the patient. Thus, the characterization of each chromosome marker becomes imperative for this correlation [15].

Among the complex karyotypes it has been found a Down syndrome (DS) presenting three clones cell. According to this finding, Silva et al. [16] found a karyotype of a DS patient involving four clones. In the literature, the relative risk of acute leukemia in the first 5 years has been estimated to be 56 times that of non-DS individuals with an equal frequency of acute myeloid leukemia (AML) or acute lymphoblastic leukemia (ALL) [17].

This study could not be supplemented by molecular approaches due to limitations in amount of patient material and technical limitations as present in many regions of the world. However, banding cytogenetics is the basics for all further studies, especially in rare malignancies like the here reported childhood leukemias.

Even though it is difficult to assume the outcome of these patients, patients with complex cytogenetic changes were classified as poor prognosis. The prognosis was considered favorable in patients with hyperdiploidy or with normal karyotype, and the age between one and six years and/or leukocyte count close to normal. The intermediate prognosis has been established for patients with karyotypes who had only one structural chromosomal alteration, aged between one and six years old, leukocyte count above $20,000 / \mu \mathrm{l}$ and response to treatment assessed by the presence of blasts in the PB. The poor prognosis group presented complex karyotype, are age over 10 years old and have the presence of blasts above $25 \%$ in PB.

Taken together these results show the importance of the cytogenetic analysis in ALL pediatric patients and illustrates that the studied population presented unexpected complexes karyotypes which were correlated to poor outcome.

\section{Material and methods \\ Study design}

Patients included were issued from 5 different hospitals of the state of Rio Grande do Norte: Hospital Infantil Varela Santiago, Liga Norte-Riograndense Contra o Câncer, Centro de Oncologia e Hematologia de Mossoró, Clínica DNA Center during the period comprised between January 1st, 2009 and November 30, 2010. The inclusion criteria were cytological and immunohistochemical diagnosis for ALL; patients aged 0-18 years; availability of biological material for cytogenetic analysis; laboratory data, such as leukocyte counts, percentage of blast cells, count platelets and hemoglobin; clinical data: presence or absence of visceromegalies. 


\section{Samples processing}

Samples of bone marrow and peripheral blood of thirty patients diagnosed with ALL of both sexes, aged from 4 months to 17 years old were collected. Cytogenetic analysis on bone marrow cells and / or peripheral blood was performed in the clinical laboratory of DNA Center. The cytochemical diagnosis, morphological and immunohistochemical were provided by company Hemonorte Hematology (Natal/RN). For cytogenetic analysis, $5 \mathrm{ml}$ of each bone marrow samples was collected in a syringe containing sodium heparin. $2-5 \mathrm{ml}$ of bone marrow were collected in a tube containing $0,1 \mathrm{ml}$ of Liquemine ${ }^{\circ}$ Roche ${ }^{\circ}$. For peripheral blood, $5 \mathrm{ml}$ were collected in a tube containing heparin. Samples were processed by centrifugation $(2.000 \mathrm{rpm})$.

\section{Cell culture}

The biological material was incubated overnight in sterile conditions, in media containing 8\% RPMI 1640 supplemented with $20 \%$ serum fetal bovine (FBS) and glutamine (GIBCO Invitrogen ${ }^{\circ}$ ). The mitotic interruption was proceed by adding $16 \mathrm{ug} / \mathrm{mL}$ colchicine (GIBCO) and incubated for 1 hour at $37^{\circ} \mathrm{C}$. Cells were submitted to hypotonic treatment with a solution of $0.075 \mathrm{M}$ potassium chloride for 20 minutes and the material were fixed with 3:1 (v/v) methanol: acetic acid. Cells were spread in the slides and dried on a heating plate.

\section{GTG-banding cytogenetics}

Karyotyping was performed using standard techniques, and the results were reported according to the International System for Human Cytogenetic Nomenclature guidelines. The slides were incubated in Sorensen's buffer for $45 \mathrm{~min}$ and then stained with Wright's stain buffer for 2 minutes. The slides were analyzed in an optical microscope (Nikon-E200). A complex aberrant karyotype was defined as three or more independent cytogenetic abnormalities in at least two bone marrow cells.

\section{Data collection}

Data were collected and entered in Microsoft Excel ${ }^{\circ}$ spreadsheet, and later, there was a descriptive analysis using SPSS Statistics 17.0, mean, median and standard deviation of patient characteristics (age, sex, color) clinical data (lymphadenopathy, hepatomegaly and splenomogaly), chromosomal abnormalities present in the samples, prognosis of abnormalities found and, finally, the parameters hematology (hemoglobin, leukocytes and platelets).

\section{Ethics consent}

This study was approved in the Ethics Committee of The Hospital Universitário Onofre Lopes (Universidade Federal do Rio Grande do Norte) under the registration number: 083/07. The written informed consent number obtained from the patient's parents for publication of this case report is retained with the same Ethics Committee.

\section{Abbreviations \\ ALL: Acute lymphoblastic leukemia; AML: Acute myeloid leukemia; BM: Bone marrow; DS: Down syndrome; PB: Peripheral blood; WBC: White blood cell.}

\section{Competing interests}

Erica Gil holds a CNPq grant and TBPL holds a CAPES grant. The remaining authors declare that they have no competing interests.

\section{Authors' contributions}

EAG made all experiments and wrote the article, TBPL, TMOM, JMF, JMF, ALACF, GDRL helped to write the manuscript and performed data collection from medical records, EMRN helped to collect and process patient samples and GBCJ helped to conduct the study as supervisor. All authors read and approved the final manuscript.

Authors' information

This study was conducted by Erica Gil, MPharm, in order to obtain Master Degree at the Pharmaceutical Program at the Universidade Federal do Rio Grande do Norte.

\section{Acknowledgements}

We are grateful to the physicians and to the patients of the four institutions who had collaborated in this work.

\section{Author details}

${ }^{1}$ Departamento de Análises Clínicas e Toxicológicas/ Laboratório de Imunologia, Universidade Federal do Rio Grande do Norte/, Rua Gen, Gustavo Cordeiro De Farias S/N. Petrópolis, CEP 59010-180, Natal, RN, Brazil. 'Liga contra o Câncer. Departamento de Pesquisa Translacional, Av. Miguel Castro 1355. Dix-Sept Rosado, CEP 59062-000, Natal, RN, Brazil.

Received: 17 April 2013 Accepted: 21 August 2013

Published: 11 September 2013

\section{References}

1. Garcia DR, Bhatt S, Manvelyan M, de Souza MT, Binato R, Aguiar TF, Abdelhay E, Silva MLM: An unusual T-cell childhood acute lymphoblastic leukemia harboring a yet unreported near-tetraploid karyotype. Mol Cytogenet 2011, 4:20.

2. Morel F, Le Bris M-J, Douet-Guilbert N, Duchemin J, Herry A, Le Calvez G, Marion V, Berthou C, De Braekeleer M: Loss of X chromosome in childhood acute lymphoblastic leukemia. Cancer Genet Cytogenet 2003, 125:27-29.

3. Debatin KM, Stahnke K, Fulda S: Hematological disorders and apoptosis. Nippon Naika Gakkai Zasshi 2003, 13:149-158.

4. Pui C-H, Relling MV, Downing JR: Acute lymphoblastic leukemia. N Engl J Med 2004, 350:1535-1548.

5. Pui $\mathrm{CH}$, Crist WM: Cytogenetic abnormalities in childhood acute lymphoblastic leukemia correlates with clinical features and treatment outcome. Leukemia lymphoma 1992, 7:259-274.

6. Perkins D, Brennan S, Carstairs K, Bailey D, Pantalony D, Poon A, Fernandes B, Dubé I: Regional cancer cytogenetics: a report on 1,143 diagnostic cases. Cancer Genet Cytogenet 1997, 96:64-80.

7. Amare P, Gladstone B, Varghese C, Pai S, Advani S: Clinical significance of cytogenetic findings at diagnosis and in remission in childhood and adult acute lymphoblastic leukemia: experience from India. Cancer Genet Cytogenet 1999, 110:44-53.

8. Caspersson T, Zech L, Johansson C, Modest EJ: Identification of human chromosomes by DNA-binding fluorescent agents. Chromosoma 1970, 30:215-227.

9. Seabright M: A rapid banding technique for human chromosomes. Lance 1971, 2:971-972.

10. Al-Achkar W, Aljapawe A, Othman MAK, Wafa A: A de novo acute myeloid leukemia (AML-M4) case with a complex karyotype and yet unreported breakpoints. Mol Cytogenet 2013, 6:18.

11. Zakaria Z, Md Ahid MF, Ismail A, Ten SK, Mohamad Nor N, Kamaluddin NR, Esa E, Kah Yuen L, Abdul Rahman EJ, Osman R: Chromosomal Aberrations in ETV6/RUNX1-positive Childhood Acute Lymphoblastic Leukemia using 
244 K Oligonucleotide Array Comparative Genomic Hybridization. Mol Cytogenet 2012, 5:41

12. Perez-Vera P, Mujica-Sanchez M, Carnevale A, Rivera-Luna R, Paredes R, Martinez A, Frias S: Cytogenetics in acute lymphoblastic leukemia in Mexican children: an institutional experience. Arch Med Res 2001, 32:202-207.

13. Pui CH, Raimondi SC, Dodge RK, Rivera GK, Fuchs LA, Abromowitch M, Look AT, Furman WL, Crist WM, Williams DL: Prognostic importance of structural chromosomal abnormalities in children with hyperdiploid (greater than 50 chromosomes) acute lymphoblastic leukemia. Blood 1989, 73:1963-1967.

14. Hasle H: Pattern of malignant disorders in individuals with Down's syndrome. Lancet Oncol 2001, 2:429-436.

15. Slovak ML, Kopecky KJ, Cassileth PA, Harrington DH, Theil KS, Mohamed A, Paietta E, Willman CL, Head DR, Rowe JM, Forman SJ, Appelbaum FR: Karyotypic analysis predicts outcome of preremission and postremission therapy in adult acute myeloid leukemia: a Southwest Oncology Group/ Eastern Cooperative Oncology Group Study. Blood 2000, 96:4075-4083.

16. Silva MLM, Ornellas De Souza MH, Ribeiro RC, Land MGP, Boulhosa De Azevedo AM, Vasconcelos F, Otero L, Vasconcelos Z, Bouzas LF, Abdelhay E: Cytogenetic analysis of 100 consecutive newly diagnosed cases of acute lymphoblastic leukemia in Rio de Janeiro. Cancer Genet Cytogenet 2002, 137:85-90.

17. Hasle H, Clemmensen IH, Mikkelsen M: Risks of leukaemia and solid tumours in individuals with Down's syndrome. Lance 2000, 355:165-169.

doi:10.1186/1755-8166-6-37

Cite this article as: Gil et al:: Banding cytogenetic analysis in pediatric patients with acute lymphoblastic leukemia (ALL) in a Brazilian population. Molecular Cytogenetics 2013 6:37.

\section{Submit your next manuscript to BioMed Central and take full advantage of:}

- Convenient online submission

- Thorough peer review

- No space constraints or color figure charges

- Immediate publication on acceptance

- Inclusion in PubMed, CAS, Scopus and Google Scholar

- Research which is freely available for redistribution 